\title{
Síndrome de Burnout y depresión en trabajadores de la Universidad Nacional del Centro del Perú - 2018
}

\author{
Burnout syndrome and depression in workers of \\ the National University of the Center of Peru - 2018
}

\author{
aHuachos Pacheco, A.; ' Veli Chuquillanqui, R.; \\ 'Barbarán Ludeña, W.; ' Huachos Borja, K.; Peña Ortiz, S. \\ Facultad de Antropología / Universidad Nacional del Centro del Perú \\ Email: ahuachos@uncp.edu.pe
}

\section{Resumen}

La presente investigación comienza con la interrogante ¿Qué relación encontramos entre el Burnout y depresión en trabajadores de la Universidad Nacional del Centro del Perú, durante el año académico 2018? cuyo objetivo fue establecer la correlación entre el síndrome de Burnout y la depresión en trabajadores universitarios.

La investigación fue de naturaleza básica. Se utilizó el método descriptivo que permitió constatar la correlación entre el Burnout y la depresión. Se empleó el diseño de investigación descriptivo correccional; El muestreo fue no probabilístico e intencional y, para ello, se ha coordinado con 150 docentes de la Universidad Nacional del Centro del Perú. Los instrumentos que se han utilizado para la investigación son: El inventario de Maslach y la escala de Hamilton.

En el estudio de los resultados obtenidos, se ha utilizado la estadística descriptiva e inferencial. Al final, se demostró la existencia de relación entre el agotamiento laboral y la depresión.

Palabras clave: síndrome de Burnout, depresión en trabajadores, docente universitario, empleado público

\begin{abstract}
This research begins with the question: What relationship do we find between Burnout and depression in workers of the National University of the center of Peru, during the school year 2018? The reason of this work was to establish the correlation between Burnout and depression in workers of the National University of the center of Peru, during the school year 2018.

The research was of a basic nature. We used descriptive method allowing to verify the correlation between Burnout and depression. The correlational descriptive research design was used; the sampling was nonprobability and intentional and for this it has been coordinated with 150 workers of the National University of the center of Peru. The instruments that have been used for research are: the inventory of Maslach and the Hamilton scale.

In the study of the results obtained has been used the descriptive and inferential statistics. In the end, the relationship between job burnout and depression was demonstrated.
\end{abstract}

Keywords: Burnout syndrome, depression in workers, university professor, public employee 


\section{Introducción}

En los últimos años, el ritmo laboral ha cambiado mucho debido a las exigencias sociales. Ahora se busca profesionales capaces de trabajar bajo presión y sean competentes; en consecuencia, los trabajadores tienen que satisfacer los deseos de sus empleadores y de aquellos a los que brindan servicios, afrontando las consecuencias que le generan estas condiciones a la salud.

Uno de los principales problemas que acontecen en la parte laboral, es el síndrome de Burnout o del quemado, ocasionado por los cambios socioeconómicos y laborales.

Gil - Monte (2018) afirma que el Burnout se da en profesionales que trabajan de manera directa con personas, porque es cansado sobrellevar conductas de otras personas. Una de estas profesiones es la docencia, debido a que las instituciones educativas responden al sistema capitalista caracterizada por la oferta y la demanda, donde se ha olvidado la verdadera naturaleza de la educación y solo se la ve como una empresa que brinda servicios.

A los maestros, que tiene que hacer frente a su profesión, les generan un agotamiento laboral que afecta su estado psicológico, porque no solo se dedican a sus estudiantes, sino también, tienen que preocuparse por las actividades administrativas y de investigación que les exige toda entidad educativa superior. Las exigencias laborales hacen que su vida familiar y social sea reducido y no puedan recrease, después de haber realizado agotadas actividades mentales en su centro de trabajo; todo lo anterior, genera en ellos estados de depresión por las constantes condiciones laborales que sobrellevan, además de realizar estudios, hacer su tesis, asistir a un congreso y buscan tener más resoluciones de felicitaciones para engordar su currículo, porque así lo exige la competencia laboral.

Zabalza (2009) afirma que son muchos los maestros que tienen que dejar a su familia para ser un buen profesional los acaba y los agota porque, son personas que no disfrutan de la vida plenamente.

El docente universitario no solo tiene que preocuparse por brindar un buen servicio a sus estudiantes; además, debe de ser sometido a encuestas estudiantiles cada semestre. Esto les genera preocupación por obtener un buen puntaje y tener mejores oportunidades laborales, pero qué sucede con aquellos que sufren de Burnout y han llegado a la depresión. Son aquellos maestros que inevitablemente van a salir mal en estas encuestas y solo esperan el desenlace de su historial laboral.

\section{Análisis teórico}

El agotamiento laboral lo explican las siguientes teorías psicosociales:

a) Teoría sociocognitiva del Yo. Harrison (1983) considera que los seres humanos, por lo general, eligen carreras profesionales para prestar ayuda a los de- más. Están predispuesto a ciertos estados emocionales, como la depresión o el estrés producto por los conflictos personales, sobrecarga laboral, etc.; con el tiempo, la persona sufre de Burnout.

b) Teoría de intercambio social. Hace referencia a las relaciones laborales que se tiene con los compañeros de trabajo. Muchos profesionales no piden ayuda a los demás, porque amenaza su autoestima y piensan que serán criticados. Tienden a comparar su trabajo con la de sus compañeros y se sienten pésimos (Buunk y Schaufeli, 1993).

c) Teoría organizacional. Consideran que los factores que desencadenan el Burnout son: rutina, monotonía y la falta de organización dentro del centro de trabajo que produce enfrentamientos entre los colegas. Todo lo anterior, genera en las personas cansancio laboral, como lo define Winnubst (1993).

\section{El Burnout}

Las personas que llegan a tener Burnout tiene problemas físicos, motivacionales y emocionales. El - Sahili (2015) afirma que es más peligroso el Burnout que la depresión, porque un docente puede vivir meses y años con desgaste laboral y nadie puede percibirlo; pero en cambio, la depresión por caracterizarse por el bajo estado anímico advierte a las personas que lo rodean y ser atendido de manera inmediata.

Expresiones constantes de maestros que padecen de Burnout:

- Me incomodan mis estudiantes, porque cada vez están peores y no sé cómo controlarlos.

- No me gusta ir a mi trabajo.

- El personal administrativo no considera que tengo mucho trabajo.

- Tengo miedo de ser despedido.

- Siento que los estudiantes perciben que mi trabajo no es el de antes.

- No puedo organizar mi trabajo de manera adecuada.

\section{Causas que generan el Burnout docente}

Las causas que provocan la existencia de Burnout en los trabajadores:

- Desilusión gradual del trabajo

- Menos control en la vida

- Preferencias a unos en detrimento a otros

- Agudización de la discrecionalidad laboral: Los docentes sienten que sus colegas son más que él, a pesar que desempeñan el mismo trabajo. Al sentir que sus colegas tienen un mejor horario que el suyo. Sienten que algunos tienen más oportunidades de crecer profesionalmente en el centro laboral.

\section{La depresión en los trabajadores}

Es una enfermedad que no es momentánea, que afecta su estado emocional y sobre todo se ha convertido en parte de la vida de todo educador. 
Se considera que una persona se encuentra en depresión cuando su tristeza es constante y esto es causado por el estrés. La depresión es la constante tristeza que presenta la persona que afecta el cuerpo y la mente. La persona no come, ni duerme, afectando su autoestima. No pueden decir voy a ponerme mejor, porque necesitan de ayuda externa para controlar los sentimientos que tienen.

\section{Factores que pueden ocasionar la depresión}

Según San y Arranz (2010):

Los genes: Se sugiere la existencia de un factor genético que permite heredar la depresión. Se debe tener cuidado si la familia lo padece.

La personalidad: Las personas obsesivas, rígidas, controladoras y que les gustan las cosas perfectas suelen estar predispuestas a la depresión, cuando no consiguen lo que quieren.

Estilo de pensamiento: Las personas que no celebran sus logros y tiene un pensamiento negativo sobre sí mismo.

Enfermedades crónicas: Tener alguna discapacidad y ser inseguros desencadenan la depresión.

Estrés y sucesos vitales estresantes: La muerte de un ser querido, pasar por un divorcio, no tener un empleo seguro y la jubilación próxima.

\section{Apreciación estudiantil sobre el desempeño docente}

Esta encuesta es personal, anónima y se realiza en cada semestre académico con el propósito de evaluar el desempeño de sus trabajadores y tomar acciones a partir de los resultados. Los resultados son remitidos a la Oficina de Escalafón Universitario para ser archivados en los files personales.

\section{Métodos y materiales}

La investigación se aplicó en trabajadores administrativos de la Universidad Nacional del Centro del Perú.

El estudio descriptivo correlacional se desarrolló por medio del cuestionario, aplicado a una muestra de 225 personas entre varones y mujeres, durante el año 2018.

Los trabajadores estuvieron distribuidos de la siguiente manera: 98 varones y 127 mujeres de edades que oscilan entre 18 a 60 años; la condición laboral es entre contratados y nombrados; la mayoría de ellos son personal auxiliar, técnico y profesional; una mínima parte son funcionarios. En primer lugar, respondieron el inventario de Maslach para síndrome de Burnout y, posteriormente, la escala de depresión de Hamilton.

Los trabajadores fueron seleccionados utilizando la técnica de muestreo de sujetos voluntarios y, estuvo comprendida por todos aquellos que se sometieron a la evaluación por su propia voluntad.

Los instrumentos utilizados fueron; para la primera variable, el inventario de agotamiento de Maslach que es uno de los instrumentos más utilizados para medir la presencia de estrés laboral o síndrome de quemado en el trabajo. In- troducido en 1981, continúa siendo probado en su estructura factorial por diversos autores (Byrne, 1993; Richarsen y Martinussen, 2004; García, Herrero, y León, 2007). Desde 1974, Cristina Maslach reconoce el "Síndrome de Burnout" (síndrome de estar quemado) en los sujetos afectados por "sobre carga emocional" debido a las características de su trabajo, como una respuesta emocional de los profesionales de ayuda. La primera versión del instrumento fue desarrollada por Maslach y Jackson, en 1981 y; la segunda versión, en 1986, esta última es la que se utiliza largamente en las diferentes investigaciones, por estar traducida al castellano.

El Maslach Burnout Inventory (MBI), es un instrumento en el que se plantea al sujeto una serie de enunciados sobre los sentimientos y pensamientos con relación a su interacción con el trabajo.

Es el instrumento que ha generado un mayor volumen de estudios e investigaciones, formado por 22 ítems que se valoran con una escala tipo Likert. El sujeto valora, mediante un rango de 6 adjetivos que van de "nunca" a "diariamente", con qué frecuencia experimenta cada una de las situaciones descritas en los ítems.

Para la variable depresión, se utilizó la Escala de Evaluación para la Depresión de Hamilton, diseñada para ofrecer una medida de la intensidad o gravedad de la depresión. La versión inicial, con 24 ítems, data de 1960 y fue posteriormente revisada y modificada por el mismo autor en 1967, reduciéndola a 21 ítems; de ellos, los cuatro últimos no son útiles a efectos de valorar la intensidad o gravedad de la depresión, por lo que en los ensayos clínicos de evaluación terapéutica se ha generalizado el uso de una versión reducida de 17 ítems, que corresponden a los 17 primeros de la versión publicada en 1967.

La versión de 21 ítems fue adaptada al castellano por Conde y Cols en 1984, quien introdujo un ítem final para valoración de otros síntomas, por lo que consta de 22 ítems. Ramos-Brieva y Cordero (1986) adaptaron al castellano y validaron la versión reducida de 17 ítems.

Para la descripción de los resultados se utilizaron tablas de frecuencias; para establecer la relación entre las variables y sus dimensiones se manejó la correlación tau-b de Kendal, mientras que la contrastación de las hipótesis se ha realizado con la prueba de significancia.

\section{Resultados}

La muestra estuvo conformada por 225 trabajadores, de las facultades de Educación, Enfermería, ingenierías, Contabilidad, Economía, Arquitectura y Sociología. En los resultados se encontró que 96 servidores, que representan al 46,67 \% sufren de Burnout, 71 tienen un Burnout moderado y 58 un Burnout bajo. Al revisar los antecedentes, se encontró en las investigaciones que los trabajadores sufren de desgaste laboral por el constante estrés en el que se encuentran sometido a día a día en su entorno de trabajo. 
La teoría sociocognitiva delYo, afirma que la carrera de Educación, por la naturaleza tan delicada y dedicada de los docentes, con el tiempo sufre de Burnout. En las encuestas, también se evidencio que la mayoría de los trabajadores sufren de estrés y no se preocupan por su salud mental, y aumentando cuando comienzan las encuestas estudiantiles.

En la aplicación de la entrevista a 60 trabajadores que sufren de Burnout alto, resultó que 31 de ellos, que corresponde al 51,67\%, sufren de una depresión severa; 14 trabajadores, que es el (23.33\%), presentan una depresión moderada y; 15 trabajadores $(25.00 \%)$, tienen una depresión menor. La naturaleza de la depresión no es fácil de estudiarlo; pero, el modelo psicodinámico explica que la protección y cariño que recibimos en la infancia es importante, ahora bien, qué se sabe de aquellos maestros que están en las aulas universitarias, si tuvieron una familia feliz y cariñosa, porque son esos aspectos que influyen en el desarrollo de la depresión, más adelante.

Además, que sucede si el docente realiza el mayor esfuerzo por cumplir son su trabajo y no recibe estímulos de sus empleadores o, más aún, de sus estudiantes, lo afirma el modelo conductual, donde el docente se siente mal porque piensa que su trabajo no es bueno y esto lo lleva al aislamiento. Los participantes, que en un principio fueron 225 , se redujeron tomando en cuenta a los que tiene mayor depresión, los cuales son 31 trabajadores, pero la muestra se redujo a 21, cuyos resultados obtenidos en la Encuesta Estudiantil 2018-I, fueron: 4 los que tiene un resultado bueno (19,05\%), regular $8(38,10 \%)$ y 9 deficiente $(42,86 \%)$. De este grupo, se toma en cuenta lo siguiente:

Primero: 6 son trabajadores nombrados y 15 son contratados.

Segundo: 7 son solteros, 5 casados y 9 divorciados.

Tercero: 8 son de sexo femenino y 13 masculino.

Cuarto: 5 están en la edad de 31 - 40, 10 entre los 41 50 y 6 entre los $51-60$.

De todo ello, se puede afirmar que los docentes que tienen problemas son los contratados, del sexo masculino, divorciados y están en la edad de 41 - 50 años. Cuando se relacionó las variables de Burnout y depresión, se evidenció que existe una relación fuerte ente ambas variables, es ahí donde se reafirma que los trabajadores que tienen mayor desgaste laboral el nivel de depresión es mayor.

En la relación de Burnout y desempeño, se debe aclarar que la relación es parcial, porque no todos los docentes, que tienen Burnout, poseen un resultado desalentador en las encuestas estudiantiles.

\section{Conclusiones}

- Con esta investigación, se demostró que existe una relación parcial entre el síndrome de Burnout, la depresión y el desempeño del docente.
- Los docentes varones, que sufren un alto nivel de Burnout, depresión severa y presentan un deficiente desempeño laboral, tienen problemas con la familia y los amigos.

- Los maestros universitarios que no tienen familia constituida y se refugian en su trabajo para sentirse útiles, sufren de depresión en comparación a los solteros y casados.

- Los docentes universitarios sienten impaciencia cuando saben que van a ser evaluados y tiene miedo de caerles antipáticos a los estudiantes para que no los jalen.

\section{Referencias bibliográficas}

Botero, C. (2012). Riesgo psicosocial intralaboral y Burnout en trabajadores universitarios de algunos países latinoamericanos. Cuadernos de administración. Universidad del Valle, 3.

Buunk, B. P. y Schaufeli, W. B. (1993). Burnout: una perspectiva de la teoría de comparación social. En W. B. Schaufeli, C. Maslach, y T. Marek (Eds.), Serie en psicología aplicada: cuestiones y preguntas sociales. Burnout profesional: desarrollos recientes en teoría e investigación. Filadelfia, Pensilvania, EE. UU: Taylor y Francis.

El-Sahili Gonzáles, L. F. (2015). Burnout. Consecuencias y soluciones. Mexico: El Mnaual Moderno.

Felipe, L. (2010). Psicologia para el docente: Consideraciones sobre los riesgos y desafíos de la práctica magisterial. Guanajuato: Universidad de Guanajuato.

Gil-Monte, P. (2002). Validez factorial de la adaptacion al español del Maslach Burnout Inventory. General Survey. Scielo Salud pública.

Gil-Monte, P. (13 de julio de 2018). Scielo Salud Pública. Obtenido de https://www.scielosp.org/ scielo. php?pid $=$ S1135-57272009000200003\& script $=_{\text {S- }}$ ci_arttext\&tlng $=p t$

Harrison, W. D. (1983). A social competence model of Burnout. En: Farber, B. A. (Ed.), Stress and burnout in the. New York: Pergamon Press.

San Molina, L. y Arranz Martí, B. (2010). El médico en casa. Comprender la depresión. Barcelona: Amat.

Vallejo Ruiloba, J. (2006). Introdución a la psicopatología y la psiquiatría. Barcelona: Masson.

Winnubst, J. A. (1993). Organizational structure, social. London: Taylor

Zabalza, M. A. (2009). Ser un profesor universitario hoy. La cuestión universitaria, 70, 71 . 